\title{
Economía política del ambiente: voz y eco en el análisis social de los problemas ambientales
}

\author{
Fabio Alberto Arias-Arbeláez*
}

\begin{abstract}
Recibido: 18 de septiembre del 2018
Evaluado: 15 de noviembre de 2018

Aceptado: 26 de noviembre del 2018
\end{abstract}

Citar como: Arias-Arbeláez, F. A. (2019). Economía política del ambiente: voz y eco en el análisis social de los problemas ambientales. Hallazgos, 16(32), 27-42. DOI: https://doi. org/10.15332/2422409X.4640

\section{RESUMEN}

Este artículo delimita el campo de trabajo de la economía política del ambiente. Se propone un marco conceptual para abordar los problemas ambientales con un enfoque que contemple tanto la esfera colectiva de la economía como las relaciones de poder y conflicto de intereses en la apropiación y uso de la naturaleza. Para acometer este objetivo general se identificaron tres tareas específicas: revisar el significado de economía política, ilustrar la relación entre economía política y los problemas ambientales y contrastar el campo de análisis de la economía política y ambiente con otros campos de trabajo complementarios como la ecología política.

Palabras clave: conflicto de intereses y naturaleza, ecología, política.

Ph. D. en Desarrollo Sustentable. Profesor asociado de la Universidad del Valle, Cali, Colombia. A. A. 25360, correo electrónico: fabio.arias@correounivalle.edu.co - ORCID: https://orcid.org/0000-0003-4589-2615. El presente artículo se desarrolló en el marco del proyecto: Estrategias para la recuperación y manejo integrado del recurso hídrico en las cuencas del Cauca y Dagua en el Valle del Cauca, financiado por el Fondo de Ciencia, Tecnología e Innovación del Sistema General de Regalías. 


\section{Political economy of the environment: voice and echo in the social analysis of environmental problems}

\begin{abstract}
This article seeks to delimit the field of work of Political Economy of the Environment. A conceptual framework is proposed to deal with environmental problems with an approach that addresses both the collective sphere of the economy and the relations of power and conflict of interest in the appropriation and use of nature. To achieve the overall objective, three specific tasks are identified: review the meaning of political economy, establish the relationship between political economy and environmental problems and contrasting the field of analysis of political economy and environment with other complementary fields of work as political ecology.
\end{abstract}

Keywords: conflict of interest and nature, ecology, politics.
Received: september 18, 2018

Evaluated: november 15, 2018

Accepted: november 26, 2018 


\section{Economia política do ambiente: voz e eco na análise social dos problemas ambientais}

Recebido: 18 de setembro de 2018 Avaliado: 15 de novembro de 2018 Aceito: 26 de novembro de 2018

\section{Resumo}

Este artigo delimita a área de trabalho da economia política do ambiente. Propõe-se um marco conceitual para abordar os problemas ambientais com um enfoque que contemple tanto a esfera coletiva da economia como as relações de poder e conflito de interesses na apropriação e uso da natureza. Para acometer este objetivo geral identificaram-se três áreas especificas: revisar o significado de economia política, ilustrar a relação entre economia política e os problemas ambientais e contrastar o campo de análise da economia política e ambiente com outros campos de trabalho complementários como a ecologia política.

Palavras-chave: conflito de interesses e natureza, ecologia, política. 


\section{INTRODUCCIÓN}

Para entender mejor cómo una sociedad contemporánea resuelve el abastecimiento material del bienestar de sus miembros, se propone recurrir a un enfoque de economía política del ambiente. La economía política revela la importancia de la esfera colectiva o pública en el abastecimiento material de una sociedad; los individuos, además de consumir, producir o intercambiar, crean y comparten una visión del mundo y de la buena vida que esperan llevar en él. Esta dimensión social adquiere mayor relevancia actualmente porque la naturaleza, que es la fuente del bienestar humano, está sensiblemente degradada, comprometiendo incluso la continuidad de la vida sobre el planeta en todo su esplendor. Las decisiones individuales de intercambio importan como elemento de análisis, no obstante, no representan el conjunto relevante de hechos económicos; las decisiones sociales se dan en escenarios conflictivos en medio de disputas desiguales en el aprovechamiento de la naturaleza. Para defender esta postura se comienza presentando los enfoques de la economía política y la nueva economía política, para luego sí delimitar el campo de trabajo de la economía política del ambiente propiamente dicho. Luego se comparan la economía política del ambiente con la ecología política porque son campos estrechamente relacionados. Por último, se concluye con una síntesis.

\section{ECONOMÍA POLÍtica}

Para delimitar el campo de trabajo de la economía política del ambiente se propone primero hacer una revisión sobre el significado de economía política. En este artículo se argumenta que este término tiene que ver con la esfera pública de las relaciones sociales en el abastecimiento material del bienestar de las personas. Quienes proponen un argumento similar son Caporaso y Levine (2009), por lo tanto, estos autores son el punto de referencia para la revisión del significado de economía política y la crítica hecha a ellos en este artículo es la base de la propuesta dada sobre la delimitación del campo de trabajo de la economía política del ambiente. Para empezar, se resume la presentación hecha por Caporaso y Levine sobre el significado de economía política. Ellos parten de la presentación de los significados de política, economía y de la síntesis de las anteriores palabras en el término economía política.

En el caso, el concepto de política se ha asociado al análisis del poder, la autoridad, la vida pública, el Estado o los conflictos. Los autores analizan tres grandes conceptualizaciones de la política: entendida como Gobierno, como vida pública o como asignación autoritaria de valores. La primera se refiere a la asociación directa entre política y Gobierno, la estructura formal de instituciones, legislación y políticas públicas que configuran el accionar de un Estado. Este enfoque es limitado porque el poder, la autoridad o los conflictos no están limitados a la esfera exclusiva del Gobierno. Por ejemplo, las disputas pueden darse entre el Gobierno y grupos de interés privados o los sistemas sociales de decisión son constituidos por redes de poder público y privado.

La segunda conceptualización es la política entendida como lo público. En la tradición de Aristóteles (2007) la política está asociada a la vida pública que es esencial para la expresión del hombre. Esta interpretación 
ha tomado dos vertientes que se basan en las concepciones de John Dewey (2012 [1954]) y Hannah Arendt (2005). Dewey concibe lo público como acciones de un individuo o grupo de individuos que superan su relación directa y tienen efectos sobre los demás. Este concepto parece muy relacionado con el neoclásico de externalidad, efectos sobre terceros que no están cobijados por la transacción de mercado. Por otro lado, para Arendt lo público puede interpretarse como una construcción intersubjetiva de la realidad. Los individuos perciben y construyen la realidad individualmente y en relación con los demás, el mundo es una construcción social, un mundo común o compartido. En este sentido, lo público no es simplemente un campo de disputa o tensión entre los intereses individuales.

La tercera concepción de la política es como asignación autoritaria (o autorizada) de valores (Easton, 2006). Bajo esta interpretación, la política se asemeja a la economía en el sentido de que ambas son métodos de asignación. Mientras en la economía se hace énfasis en el intercambio voluntario, el sistema de asignación político involucra autoridad en el proceso de decisiones acerca de la producción y la distribución. Así, la distinción de la disciplina de la ciencia política no está centrada directamente en el Estado, el poder o los conflictos, sino en las relaciones sociales vinculadas por la asignación autorizada de valores.

Caporasso y Levine (2009) concluyen “... la política se refiere a las actividades e instituciones relacionadas con la toma de decisiones públicas autorizadas para la sociedad en su conjunto" (p. 20). Esta definición comparte la intersección de tres dimensiones: la pública, el Gobierno y la autoridad. No toda la dimensión pública es política, solo aquella fracción que se relaciona con el Gobierno y las relaciones de autoridad. A la vez, no todas las acciones gubernamentales son políticas, aquellas que involucren decisiones colectivas e imposiciones de autoridad. Y la autoridad es política cuando moldea decisiones colectivas que pueden llegar a incluir al Gobierno.

Por otro lado, Caporaso y Levine (2009, pp. 21-32) señalan que hay varios significados del término economía. Las definiciones no son plenamente excluyentes, pero tienen énfasis en algunos elementos particulares que llevan a formas distintas de pensar lo que es economía. La primera conceptualización hace referencia a la economía como cálculo económico. Este enfoque se concentra en una forma de análisis que vincula a los individuos con el mundo, el esfuerzo del ser humano para enfrentar dificultades como los recursos escasos y cómo se satisface en la medida en que tenga acceso a ellos. Esa concepción realza una relación entre medios y fines, donde se destaca la elección restringida del individuo y la eficiencia del resultado.

La segunda forma de concebir la economía es como provisión material. Este enfoque se centra en el propósito de una actividad, la producción de bienes o la provisión material requeridos por una sociedad y no en la forma de cálculo de los individuos. Existe una relación material obvia entre los miembros de una sociedad dada por los bienes que producen e intercambian (Marx y Engels, 1975). Así, la economía no es otra cosa que el proceso material que sustenta la vida humana. En consecuencia "el enfoque de la provisión centra nuestra atención sobre necesidades básicas y los bienes que sostienen 
la vida en su más elemental sentido" (Caporaso y Levine, 2009, p. 25), esto lleva a considerar un sistema de necesidades entrelazado por hechos sociales objetivos y no por decisiones privadas subjetivas.

Por último, la tercera forma de concebir la economía es como una institución social e histórica específica. Una institución de "propiedad privada y contratos... que nos envuelve en un conjunto de relaciones con otros en una orientación específica para nuestros fines privados" (Caporaso y Levine, 2009, p. 29). En este caso se separa de la concepción del cálculo individual para poner énfasis en las relaciones sociales mediadas por la propiedad y el intercambio, reconociendo que los individuos buscan su propio interés. Así, los autores insisten en la noción de separabilidad, es decir, dar una definición que sea capaz de distinguir el campo de la economía de otras esferas del conocimiento sin negar que haya relación con ellas.

Se considera que la revisión de Caporaso y Levine (2009) desaprovecha elementos relevantes sobre la esfera pública de la economía política. Para empezar, si la economía se refiere a una institución sobre derechos de propiedad y contratos, entonces la política tiene que ver con la autorización de estos derechos y que regularmente son establecidos y regulados por el Estado, de tal manera que es fácil hacer coincidir la política y la economía. Pero el análisis de Caporaso y Levine sobre lo público no se lleva a la definición de economía. Para estos autores la economía es una relación social de intercambio entre individuos siguiendo sus propios intereses, este enfoque olvida la concepción de lo público, los sistemas de decisión a veces cobijan la esfera pública y no simplemente se reservan a las relaciones individuales de intercambio.

Se puede usar un problema ambiental contemporáneo como el cambio climático para ilustrar el argumento, aunque la presentación amplia del tema ambiental se hará más adelante. Hay evidencia que el cambio climático global se debe a la acción del hombre por la emisión de gases de efecto invernadero, principalmente por la quema de combustibles fósiles; la concentración de $\mathrm{CO}^{2}$ en la atmósfera sobrepasa actualmente las 400 ppm, mientras el promedio en los últimos 800 mil años, antes de la revolución industrial, había oscilado entre las 150 y 300 ppm. Esta mayor concentración de $\mathrm{CO}^{2}$ en la atmósfera produce efectos que van desde cambios extremos en el clima planetario hasta reducciones en la humedad del suelo que limitaría la producción agrícola global (Sachs, 2014).

El entendimiento de este problema y una solución es un asunto de la economía política (con el apoyo de otras disciplinas, por supuesto). La base del problema es el crecimiento económico considerado como la fuente del bienestar de los seres humanos, pero a la vez el origen de la degradación ambiental y de la alta generación de emisiones de $\mathrm{CO}^{2}$. Una solución genuina pasará por redefinir qué es bienestar humano y el procedimiento colectivo para alcanzarlo. Por ejemplo, una reformulación del sistema de mercado, nuevas formas autorizadas de consumo o intercambio, o cualquiera otra forma de organización social. Lo relevante es el aspecto colectivo de la definición del bienestar y sus formas concretas de abastecimiento material que no pasan simplemente por relaciones de intercambio. Antes de abordar en pleno el tema ambiental en la 
economía política conviene presentar una variante actual de este campo.

\section{Nueva eCONOMía POLÍtica}

Hay un campo de trabajo contemporáneo denominado nueva economía política (NEP), que busca nuevos elementos para el análisis económico mientras quiere conservar elementos valiosos de la economía política tradicional. Algunos autores tienen un renovado interés de cómo la política (o una institución) determina los resultados económicos, otros en extender el método económico moderno de modelación y análisis empírico al análisis político relacionado con la economía (Inman, 1987). Para describir la NEP se recurre a Drazen (2000), quien propone un modelo conceptual de lo que sería una economía política, y a Besley (2007), quien realiza una delimitación de este campo de trabajo.

Drazen apuesta a establecer un marco conceptual sobre economía política. El autor señala que “... la economía política comienza con la naturaleza política de la toma de decisiones y se preocupa de cómo la política afecta las decisiones económicas en una sociedad" (p. 5). Para avanzar en la conceptualización el autor precisa qué política se relaciona con el ejercicio del poder y la autoridad. El primero es la habilidad que tiene un individuo o grupo de alcanzar sus objetivos y la autoridad como situación en la cual un individuo o grupo permite que alguien más tome una decisión en su nombre explícita o implícitamente.

La base de la economía política es la heterogeneidad de intereses. Así que lo relevante para Drazen es preguntarse cómo la sociedad hace elecciones colectivas donde los individuos tienen intereses en conflicto. Incluso también se pregunta, aunque no se desarrolla en el texto, cómo un individuo o grupo buscará influir en la elección social que refleje sus intereses. En resumen, se concibe la política como el estudio de los mecanismos de toma de decisiones colectivas, lo que involucra diferentes formas en que la autoridad y el poder son ejercidos.

Por otro lado, una revisión que busca delimitar el campo de acción de la NEP es el trabajo de Besley (2007). Para el autor la NEP presta mayor atención al diseño institucional y a la aplicación de las políticas públicas, en contraste con el enfoque económico pigouviano de la intervención óptima ante fallas de mercado. Besley asume que las sociedades actuales se basan en mercados competitivos y la propiedad privada para la producción y distribución de bienes, pero también operan regularmente bajo el contexto de democracias representativas. En ese sentido, para este autor es necesaria una teoría que aborde la intervención gubernamental, por lo tanto, se requiere entender los procesos de toma de decisiones en diferentes escenarios institucionales y sus efectos económicos. Según la propuesta de Besley, se puede deducir un traslape entre la NEP y el nuevo institucionalismo.

\section{ECONOMÍA POLÍTICA DEL AMBIENTE}

Uno de los primeros autores que propusieron hablar de economía política del ambiente fue Sachs (1980), quien reconoció de manera visionaria el carácter político de los problemas ambientales e identificó algunos actores y sus posturas. El campo de estudio 
de la economía política del ambiente puede ser construido a partir de revisiones de la teoría, identificando problemas para definir prioridades de estudio, centrado en discusiones que giran en torno a discusiones ambientales y reconociendo que cualquier resultado sobre el asunto trae consigo acciones colectivas de grupos de individuos. Para encontrar las tendencias de las discusiones ambientales, Sachs clasifica en seis grupos las posiciones de análisis: diversionistas, grandes empresas, neomalthusianos, institucionalismo, primera tendencia radical y segunda tendencia radical.

Los diversionistas son grupos de personas que consideran que las preocupaciones ambientales se presentan de forma alarmista y que existen otros problemas sociales de igual o mayor relevancia por atender. Por su parte, las grandes empresas son ambivalentes frente a los problemas ambientales: unas se preocupan por los costos que les pueda generar la regulación ambiental, mientras que otras ven una oportunidad de obtener ganancias. Por otro lado, para los neomalthusianos la preocupación ambiental es evidente ya que no solo los alimentos, sino también los recursos del planeta son escasos. A su vez, para los institucionalistas la cuestión ambiental requiere la creación de organismos que velen por la calidad ambiental.

Los otros dos grupos de análisis, diametralmente opuestos, son la primera y segunda tendencias radicales. La primera tendencia radical expone que la preocupación ambiental generalmente no es un tema de las clases trabajadoras o de los pobres, sino que es una preocupación de las clases media y alta que tienen interés en medidas de conservación. Por otro lado, la segunda tendencia radical tiene un punto de vista diferente, las preocupaciones ambientales son un tema de las personas pobres que son las principales afectadas. De esta manera, la segunda tendencia radical no ve el tema ambiental como un desvío de otros temas importantes, sino como una provocación para la "acción de las masas" (Sachs, 1980, p. 300).

A pesar de la temprana identificación de la necesidad de un enfoque de economía política del ambiente, solo recientemente se encuentra una reflexión sistemática sobre el tema en el trabajo de Boyce (2002). Este autor postula que la degradación ambiental es causada por la desigual distribución de la riqueza y el poder. Generalmente las personas ricas y poderosas obtienen mayores beneficios del uso del ambiente mientras soportan poco los costos de su degradación. Bajo estas circunstancias se propone fortalecer el sistema democrático para controlar el abuso del poder de los ricos y que brinde instrumentos a los pobres para prevenir este abuso. El autor da evidencia de su tesis con trabajo empírico que ilustra cómo los

[...] países con una distribución de ingresos más equitativa, mayores derechos políticos y libertades civiles, y tasas más altas de alfabetización de adultos (indicadores de una distribución más equitativa del poder) tienden a tener menos contaminación del aire, menos contaminación del agua y un mayor acceso al agua potable e instalaciones sanitarias. (P. 5).

Para Boyce (2002), el uso que una sociedad haga de la naturaleza es determinado por las relaciones de economía política. La economía política trata "no solo acerca de 
la asignación de recursos escasos entre fines en competencia, sino también entre personas en competencia" (p. 7), con desiguales dotaciones de riqueza y de poder. Es decir, el campo de trabajo de la economía política y el ambiente es el análisis de la protección de la calidad ambiental como un proceso de decisión social determinado por la distribución de la riqueza y el poder. Así, en este enfoque la distribución es el tema central ya sea desde el aspecto normativo, la mejor distribución para obtener los resultados deseados de calidad ambiental o desde el punto de vista positivo para entender cómo el mundo funciona.

El marco analítico de la economía política y el ambiente puede sintetizarse en la identificación de los ganadores y perdedores de las decisiones ambientales y en la discriminación de las dimensiones de poder que pueden caracterizar la decisión. En el primer asunto las preguntas orientadoras son: ¿quiénes son los ganadores?, ¿quiénes son los perdedores?, y ¿por qué los ganadores consiguen imponer costos a los perdedores? Las dos primeras preguntas corresponden a un ejercicio de identificación. La respuesta a la tercera pregunta tiene tres opciones: a) los perdedores no existen todavía, pertenecen a una generación futura; b) los perdedores no tienen información sobre los efectos de la calidad ambiental sobre su bienestar $\mathrm{y}, \mathrm{c})$ los perdedores conocen su situación, pero carecen del poder de prevenir que se les impongan costos ambientales (Boyce, 2002, pp. 4-5).

Por supuesto, el poder es central en el enfoque de Boyce (2002, pp. 8-9) y lo clasifica en 5 dimensiones. El poder de compra, asociado a la disponibilidad a pagar de los individuos por bienes en escenarios de mercados, haciendo uso de su soberanía como consumidor. Poder de decisión, corresponde al caso donde alguien es capaz de imponer sus preferencias ante otros. Poder de agenda, es la habilidad de determinar cuáles son los temas de interés público a tratar en un escenario de elección colectiva. Poder de valor, cuando es capaz de influir sobre lo que otros desean y, por último, poder de determinar las circunstancias de decisión más que la capacidad de influir en la decisión. Las últimas cuatro opciones corresponden a dimensiones de poder no estrictamente económicas y son las que caracterizan situaciones ambientales en las cuales los ganadores pueden hacer soportar costos a los perdedores.

En resumen, para Boyce la distribución equitativa del poder y de la riqueza son condiciones para la protección del ambiente. El autor reconoce que la democracia no es la solución general y fácil a los problemas ambientales ni que la fortaleza de las políticas ambientales depende exclusivamente de la fortaleza de la democracia. No obstante, ofrece algunos mecanismos para propender por una mayor democracia en el uso de la naturaleza: primero, aumentos en el acervo de capital natural al cual los pobres tienen acceso; segundo, redistribución del capital natural desde las élites hacia lo pobres; tercero, aumentar la habilidad de los pobres por obtener beneficios de los activos ambientales que ya poseen y, cuarto, establecer derechos igualitarios a los recursos de libre acceso.

Otro esfuerzo por discutir qué es economía política del ambiente se debe a Rudel, Roberts y Carmin (2011). Los autores señalan 
que es un campo de estudio confuso donde hay aportes, a veces contradictorios, de disciplinas como la sociología, la ciencia política, la geografía y la economía. Ellos proponen una revisión desde la sociología para clarificar este campo de trabajo. Según ellos, la economía política del ambiente "se refiere a cómo la gente controla y, periódicamente, lucha por el control de las instituciones y organizaciones que producen y regulan los flujos de los materiales que sustentan a las personas" (p. 222). Los actores considerados regularmente en este campo de análisis son el Estado, las corporaciones y los movimientos sociales.

Rudel et al. (2011) hacen una revisión de la economía política del ambiente dividida en dos grandes grupos de trabajo: primero, las teorías centradas en la producción, segundo, la respuesta institucional y la movilización ambiental. En el primer caso, durante los años setenta y ochenta, se consideró a la producción a gran escala como la causa de la degradación ambiental; los altos efectos negativos sobre el ambiente son resultado de la creciente población humana, el creciente consumo per cápita y de la tecnología que requiere altos usos de recursos naturales por unidad de producción ${ }^{1}$. Un sistema económico donde las empresas están centradas en la generación de beneficios y un Estado enfocado en la generación del empleo y en el crecimiento económico sin atención real sobre el ambiente ${ }^{2}$.

Por su parte, la respuesta institucionalista y la movilización ambiental coinciden con

1 Rudel et al. (2011) se apoyan en el trabajo de Ehrlich y Holdren (1971).

2 Rudel et al. (2011) siguen el argumento de Gould y Schnaiberg (2008). la segunda fase de análisis de la economía política del ambiente. En esta fase aparece la acción colectiva como contraposición a las fuentes de la degradación y con la capacidad de restaurar o proteger el ambiente. Esta respuesta se da en el nivel institucional, donde los Estados asumen nuevas funciones de regulación y las organizaciones socioambientales en sus objetivos de constitución y acción. Pero además, en los movimientos socioambientales que confrontan a los responsables de los efectos negativos de la producción capitalista sobre el ambiente.

La nueva economía política también incursiona en los temas ambientales directamente. Por ejemplo, Menaldo (2015) recopila explicaciones sobre el uso del petróleo u otros recursos mineros en economías de América Latina y su crecimiento económico. Regularmente se asume que los Estados cobran impuestos a las personas porque es más fácil que a los capitales que son flujos difusos de detectar. Esto es cierto en países que no cuentan con recursos naturales, pero cuando los hay, el Estado sustituye la fuente de los ingresos con la explotación de la naturaleza (Ross, 1999, 2001). Menaldo (2015, p. 165) indica que no es necesariamente la única vía, puesto que hay países que usan parte de los ingresos de la explotación de petróleo para mejorar sus sistemas de cobros de impuestos al consumo y al comercio internacional. Este trabajo no parte de un marco o enfoque conceptual unificado de economía política, se basa en observaciones sobre decisiones de grandes actores (Estados, empresas internacionales o nacionales), sobre petróleo $\mathrm{y}$ otros recursos naturales y se indaga sobre la lógica de apropiación y usufructo. La virtud de este trabajo está en que aborda 
problemas específicos con explicaciones que involucran grandes actores de decisión.

Hasta aquí se puede hacer un balance de la bibliografía revisada antes de introducir la siguiente sección. Desde el reconocimiento en los años setenta de que la naturaleza recibía fuertes alteraciones por la expansión de la actividad económica, hay un llamado a reevaluar la disciplina de la economía. El enfoque de economía política del ambiente surge como una alternativa analítica y como justificación de la movilización colectiva para contrarrestar la degradación ambiental. Las contribuciones en este campo son esporádicas o dispersas, por lo que no se puede afirmar que hay un campo de trabajo plenamente delimitado. No obstante, hay un rescate de la tradición de la economía política aplicada a problemas ambientales con una base común: el carácter colectivo de las decisiones sobre el ambiente en una sociedad con heterogeneidad de intereses y asimetría en la distribución del poder y de la riqueza. Esta base común es compartida y ampliamente desarrollada en la ecología política, campo de trabajo que amerita al menos una breve presentación para brindar más elementos antes de finalizar la delimitación de la economía política del ambiente en una última sección de síntesis analítica.

\section{ECOLOGÍA POLÍTICA Y ECONOMÍA POLÍTICA}

Para la economía neoclásica el sistema de derechos de propiedad privada y la asignación por mercados competitivos es el mundo ideal y cualquier desviación es pequeña y debe corregirse para retornar a él. Los bienes ambientales a veces son de características públicas sobre los cuales no operan otorgamiento de derechos de propiedad o asignación por mecanismos de mercado. El uso cuidadoso de la naturaleza involucra un conocimiento complejo de los ecosistemas, flujos de energía y materiales. Esta es la demanda básica de la economía ecológica frente a la economía convencional, tener en cuenta seriamente a la naturaleza, porque el sistema económico está incrustado en ella y puede menoscabar la capacidad de la naturaleza para proveer los materiales y energía que la soportan. Este es un campo de trabajo interdisciplinar dinámico y creciente, con bases iniciales en la economía, la biología y las ciencias naturales.

Un campo de trabajo de desarrollo paralelo a la economía ecológica y que también relaciona la economía (política) con el ambiente es la ecología política. Mientras la economía ecológica se centró inicialmente en los aspectos biofísicos de la relación de la producción con la naturaleza: fuente de materiales y recepción de residuos; la ecología política centra la atención en que las sociedades están inmersas en relaciones de poder desiguales que determinan también la distribución desigual de los beneficios o costos del usufructo del ambiente. Los economistas han contribuido y recurrido a la economía ecológica como a la ecología política para replantear los aspectos relevantes de la relación entre economía y naturaleza. Por una parte, la economía ecológica, como ya se dijo, contrajo nexos con las ciencias naturales, pero mantiene la base del análisis económico en su núcleo de análisis; por otro lado, la ecología política tuvo su origen en la geografía, la antropología y la economía política.

No es difícil encontrar los nexos que algunos investigadores atribuyen entre la economía 
política y la ecología política. Martínez Alier (2009) ha hecho explícita esta relación al afirmar que: “En parte la ecología política se superpone a la economía política, que en la tradición clásica es el estudio de los conflictos de distribución económica" (p. 105). Es decir, que aquella economía política que se ocupa de los problemas ambientales sería equivalente en cierto grado a la ecología política, en otras palabras, la economía política del ambiente y la ecología política se traslapan. Es más, Martínez Alier (2009, p. 322) manifiesta que la ecología política a la que recurre para su análisis es la definida por Brosius (1999): “... una fusión de la ecología humana con la economía política... una serie de actores, con diferentes niveles de poder e intereses distintos, que se enfrentan a las demandas de recursos de parte de otros actores en un contexto ecológico particular" (p. 17).

De forma general, no existe una definición unívoca sobre ecología política, existen varias versiones con énfasis distintos, pero algunos autores han reconocido que este campo de trabajo tiene raíces en la economía política. "Algunas definiciones colocan énfasis en la economía política, mientras otras apuntan a instituciones políticas más formales, otros identifican el cambio ambiental como lo más importante, mientras otros colocan énfasis sobre las narrativas o historias de este cambio" (Robbins, 2012, p. 14). Algunos enfoques han identificado en la ecología política una síntesis, como se dijo arriba, entre economía política y la ecología humana o de forma más comprensiva como una "confluencia entre las ciencias sociales con arraigo ecológico y los principios de economía política" (Peet y Watts, 1996, p. 6).
La ecología política tiene tradición en lo que Robbins ha denominado la definición amplia de la economía política. No hay una explicación completa del uso, sobreexplotación o degradación del ambiente y de los cambios ambientales, sino hay una explicación de quién se beneficia de tales cambios y sin conocer quién toma qué de quién. Para Robbins, la definición reducida de la economía política, asociada al enfoque marxista, está concentrada en la apropiación del trabajo o la propiedad privada, pero cuando se incluyen las relaciones de poder en el uso de la naturaleza, se extiende el campo de análisis bajo los mismos principios de análisis sobre el ejercicio del poder en la apropiación del trabajo, ahora al ambiente.

Para otros autores, la ecología política tiene su propia evolución, aunque inicialmente haya estado vinculada a la economía política. Escobar (2010) habla de tres generaciones de la ecología política. La primera generación (años setenta) buscaba llenar los vacíos de la ecología humana y cultural sobre el poder y el olvido de la naturaleza en la economía política. Esta postura coincide con la síntesis señalada anteriormente. La segunda generación (años ochenta y noventa), corresponde a la consolidación de un campo de investigación interdisciplinar mayor, marcada por las tendencias teóricas posestructuralista, posmarxista y poscolonialista, con un fuerte compromiso con las discusiones epistemológicas constructivas antiesencialistas. La tercera generación, actual y en construcción, según Escobar (2015), recoge el giro ontológico en las ciencias sociales; las luchas de las comunidades en sus territorios están configuradas por la defensa de ontologías relacionales (mundos interconectados), donde se genera 
conocimiento para contraponerse a la crisis socioambiental.

Cabe señalar que la economía política basada en la crítica de Marx (1980 [1959]) ha tenido un papel en el origen de la ecología política, no obstante, el marxismo ecológico ha mostrado un desarrollo independiente. Foster (2004) se ha preocupado por demostrar que el enfoque marxista tiene mucho que ofrecer en el análisis de la crisis ambiental. Tal análisis requiere un abordaje desde el materialismo y la dialéctica; en el primer caso se parte de reconocer la estrecha dependencia que tiene el hombre de la naturaleza, en oposición al constructivismo radical que percibe a la naturaleza como una representación humana. En el segundo caso, la dialéctica sirve para abordar un mundo en continua transformación y con interrelaciones entre todos los elementos biofísicos y humanos. Foster indica que Marx no abordó el tema ecológico directamente, pero argumenta que tampoco lo desconoció de plano y lo que se quiere subrayar es que el abordaje materialista sirve para “... trascender el idealismo, el espiritualismo y el dualismo de gran parte del pensamiento verde contemporáneo" (p. 44).

El debate más reciente sobre marxismo ecológico mantiene la posición anterior. Sabbatella y Tagliavini (2011) coinciden en que la naturaleza hace parte de la obra de Marx, aunque de forma fragmentada y en segundo plano frente a los temas de producción capitalista, el capital y el trabajo, y además, que Marx previó la crisis ambiental a través de la degradación del capitalismo, pero no profundizó en ello. Entre algunos elementos básicos para retomar están la concepción materialista de la naturaleza como se expuso anteriormente, pero además la alienación no solo del trabajador de su producto sino del hombre de la tierra, la expansión capitalista que requiere la ampliación de los valores de cambio de una producción de gran escala que es dependiente a su vez del mayor uso y degradación de la naturaleza. En resumen, no se busca demostrar que Marx fuese ambientalista, sino "reapropiarnos de la crítica de la economía política para facilitar la crítica de la economía-política-ecológica" (p. 11).

Una postura radical se ha configurado en el ecosocialismo (Löwy, 2015). Este es un movimiento intelectual y activista que parte de reconocer que la degradación ambiental actual configura una crisis civilizatoria y amerita transformaciones radicales. Este movimiento busca romper con la tradición marxista de progreso por medio del productivismo y del consumo, que son la fuente de la destrucción de la naturaleza. Propende por resaltar los valores de uso en lugar de los valores de cambio, una producción que satisfaga las necesidades sociales y no el principio del lucro, mientras se cumplen las exigencias de la protección ambiental y una sociedad que asume la "propiedad colectiva de los medios de producción, una planificación democrática que permita a la sociedad definir los objetivos de la producción y las inversiones, y una nueva estructura tecnológica de las fuerzas productivas" (p. 48).

\section{Síntesis analítica}

La esfera pública de la sociedad es un elemento esencial en el enfoque de la economía política. La economía tiene que ver con relaciones de propiedad, producción e 
intercambio entre individuos, también con las decisiones individuales de consumo o producción y su agregación. Pero lo que en este texto se argumenta es que la economía se desenvuelve en una esfera pública, en donde las personas configuran y comparten un mundo en el cual se valida y revisa la idea del bien común. El análisis de cómo se definen objetivos colectivos en términos de bienestar material de las personas y los mecanismos para llevarlos a cabo, es el área de trabajo de la economía política y no simplemente el estudio de decisiones de mercado porque reflejan relaciones de intercambio.

La economía política está en el ámbito de las decisiones colectivas, que remiten a la vez a la forma en que el poder es ejercido en el aprovisionamiento material del bienestar. El escenario de análisis está compuesto por la heterogeneidad de intereses, regularmente contrapuestos, donde prevalecerían aquellos de quien cuenta con el poder de imponerlos. La economía política no parte ni desemboca en un ejercicio de optimización social, en el cual se presume que las elecciones libres e individuales garantizan el mayor bienestar individual y a la vez el mayor bienestar colectivo. La economía política tampoco asume que los obstáculos a la consecución de un óptimo resultado se deben a fallas en las condiciones ideales en que el mercado debe operar y por tanto deben restablecerse tales condiciones.

La economía política remite a una concepción de la economía como arte (Mill, 1944; Keynes, 1891). Arte entendido como el “... conjunto de preceptos y reglas necesarios para hacer algo" (RAE, 2016, p. 219). La interpretación de la economía como ciencia se basa en la obtención de explicaciones generales de comportamientos en mercados; consumidores y productores actuando bajo el supuesto de racionalidad generan patrones explicables bajo los principios de la observación y la verificación empírica de hipótesis. Dicha faceta no se niega aquí. Pero este aspecto es un subproducto de una organización histórica, basada en que la libertad en el intercambio y la producción (los preceptos y las reglas), son la base del máximo bienestar de los individuos y de una sociedad (lo que se busca realizar).

La economía política del ambiente retoma la tradición de la economía política. La economía no solo tiene que ver con la asignación eficiente de recursos sino con la competencia entre las personas por estos recursos, incluido el uso de la naturaleza. La clave para entender y controlar la degradación ambiental está en entender y controlar la desigualdad en la distribución de la riqueza y el poder. Donde la primera alternativa para definir límites en el usufructo de la naturaleza es la realización de decisiones por mecanismos democráticos para reducir los excesos de ricos y poderosos sobre los pobres o excluidos. Esta postura no es un maniqueísmo, reduccionismo de la realidad entre malos y buenos, sino una postura analítica y normativa que parte de la corroboración empírica de que los pobres reciben gran parte de los efectos negativos de la degradación ambiental.

La antigua demanda de atención sobre la distribución de la riqueza y la más reciente sobre los problemas ambientales son los temas centrales de la economía política del ambiente. Esta combinación de problemas exige renovaciones en la teoría y en la política económica. La incorporación del 
ambiente implica la revisión sobre lo que es bienestar, cuánto es posible y cómo alcanzarlo; la comprensión de la nueva configuración de actores y la interacción de sus intereses o desentrañar y regular la compleja relación entre la organización económica de una sociedad y la naturaleza. Además, este campo más amplio de trabajo no es exclusivo de la economía, es compartido al menos por la historia, la ciencia política, la sociología, la geografía y las ciencias de la tierra.

La economía política del ambiente es una voz activa en la discusión de los problemas ambientales. No es la voz predominante, pero existe como una alternativa de análisis crítico, que en algunos casos lleva a sugerir modificaciones democráticas sustanciales y en versiones más radicales la modificación total del sistema social de provisión de bienestar. Pero a la vez es el eco, no como voz en decadencia sino como una semilla que da lugar o acompaña otros esfuerzos analíticos y de acción como la ecología política. Una voz, a veces en tono bajo, que confronta la consciencia colectiva de la disciplina económica alertando sobre la relevancia de la inclusión de la esfera pública de los problemas económicos. $\mathrm{O}$ por lo menos asemeja un eco perpetuo que transporta el recuerdo que tal tarea importa.

\section{Referencias}

Arendt, H. (2005). La condición humana. Madrid, España: Paidós.

Aristóteles. (2007). La Política. Buenos Aires, Argentina: Losada.

Besley, T. (2007). The new political economy. The Economic Journal, 117(524), F570-F587.
Boyce, J. K. (2002). The political economy of the environment, Northampton, Reino Unido: Edward Elgar. DOI: https:/doi. org/10.1111/j.1468-0297.2007.02097.x

Brosius, J. P. (1999). After nature: Steps to an antiessentialist political ecology. Current anthropology, 40(1), 1-30. DOI: https:// doi.org/10.1086/515799

Caporaso, J. A., y Levine, D. P. (2009). Theories of political economy. Cambridge, MA: Cambridge University Press.

Dewey, J. (2012 [1954]). The public and its problems. Denver, CO: Penn State Press, Alan Swallow.

Drazen, A. (2000). Political economy in macroeconomics. Princeton, NJ: Princeton University Press.

Easton, D. (2006). Esquema para el análisis político. Buenos Aires, Argentina: Amorrortu.

Escobar, A. (2010). Ecologías políticas posconstructivistas. Revista Sustentabilidades, 2, 2-5.

Escobar, A. (2015). Territorios de diferencia: la ontología política de los "derechos al territorio". Cuadernos de Antropología Social, 41, 25-38. DOI: https://doi. org/10.5380/dma.v35i0.43540

Ehrlich, P. R., y Holdren, J. P. (1971). Impact of population growth. Science, 171(3977), 1212-1217. DOI: https://doi.org/10.1126/ science.171.3977.1212

Foster, J. B. (2004). La ecología de Marx: materialismo y naturaleza. Mataró, España: Editorial El Viejo Topo.

Gould K., Pellow D., y Schnaiberg A. (2008). The treadmill of production: Injustice and unsustainability in the global economy. Boulder, CO: Paradigm.

Inman, R. P. (1987). Markets, governments, and the "new" political economy. In Handbook of public economics (Vol. 2, 
pp. 647-777). Elsevier. DOI: https://doi. org/10.1016/s1573-4420(87)80007-1

Keynes, J. N. (1891). The scope and method of political economy. Londres, Reino Unido: Macmillan.

Löwy, M. (2015). Ecosocialismo. La alternativa radical a la catástrofe ecológica capitalista, Bogotá D. C., Colombia: Caña Verde.

Martínez Alier, J. (2009). El ecologismo de los pobres, Barcelona, España: Icaria.

Marx, K. (1980 [1959]). Contribución a la crítica de la economía política, México D. F., México: Siglo Veintiuno Editores.

Marx, K., y Engels, F. (1975). La ideología alemana, Bogotá D. C., Colombia: Arca de Noé.

Menaldo, V. (2015). The new political economy of natural resources in Latin America. Latin American Politics and Society, 57(1), 163-173. DOI: https://doi. org/10.1111/j.1548-2456.2015.00263.x

Mill, J. S. (1944). On the definitions of political economy, and on the method of investigation proper to it. Londres, Reino Unido: Longsmans.

Peet, R., y Watts, M. (1996). Liberalization ecology: Development, sustainability, in the environment in the age of market triumphalism. En Peet, R., Watts, M., Liberalizations ecologies. Environment, development and social movements. Nueva York: Routledge. DOI: https://doi. org/10.4324/9780203286784
Real Academia Española - RAE. (2016). Diccionario de la Lengua Española. Madrid, España: Espasa. DOI: https://doi. org/10.5944/epos.17.2001.10203

Robbins, P. (2012). Political ecology. A critical introduction. Malden, MA: Wiley-Blackwell.

Ross, M. L. (1999). The political economy of the resource curse. World politics, 51(2), 297-322.

Ross, M. L. (2001). Does oil hinder democracy? World politics, 53(3), 325-361. DOI: https://doi.org/10.1353/wp.2001.0011

Rudel, T. K., Roberts, J. T., y Carmin, J. (2011). Political economy of the environment. Annual Review of Sociology, 37, 221-238. DOI: https://doi.org/10.1146/ annurev.soc.012809.102639

Sabbatella, I., y Tagliavini, D. (2011) Marxismo ecológico: elementos fundamentales para la crítica de la economía-política-ecológica. Herramienta, 47, 3-12.

Sachs, I. (1980). Approaches to a political economy of environment. En Sachs, Ignacy, Studies in political economy of development (pp. 294-308). Nueva York: Elsevier. DOI: https://doi.org/10.1016/ b978-0-08-022495-4.50017-9

Sachs, J. (2014). La era del desarrollo sostenible. Bogotá D. C., Colombia: Paidós. 